Journal of

\section{Synchrotron}

Radiation

ISSN 0909-0495

Received 24 April 2012

Accepted 5 October 2012

\title{
Beam-induced oxidation of monomeric U(IV) species
}

\author{
Daniel S. Alessi, ${ }^{a}$ Benjamin Uster, ${ }^{a}$ Camelia N. Borca, ${ }^{b}$ Daniel Grolimund ${ }^{b}$ and \\ Rizlan Bernier-Latmani ${ }^{\mathrm{a}}$
}

a Environmental Microbiology Laboratory, Ecole Polytechnique, Fédérale de Lausanne, Switzerland, and

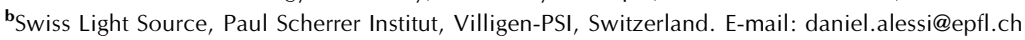

\begin{abstract}
Uranium $L_{\mathrm{III}}$-edge $\mathrm{X}$-ray absorption spectroscopy is often used to probe the oxidation state and coordination of uranium in environmental samples, and micrometre-sized beams can be used to spatially map the distribution of uranium relative to other elements. Here a variety of uranium-containing environmental samples are analyzed at both microbeam and larger beam sizes to determine whether reoxidation of U(IV) occurred. Monomeric U(IV), a recently discovered product of $\mathrm{U}(\mathrm{VI})$ reduction by microbes and certain ironbearing minerals at uranium-contaminated field sites, was found to be reoxidized during microbeam $(3 \mu \mathrm{m} \times 2 \mu \mathrm{m})$ analysis of biomass and sediments containing the species but not at larger beam sizes. Thus, care must be taken when using X-ray microprobes to analyze samples containing monomeric U(IV).
\end{abstract}

C 2013 International Union of Crystallography Printed in Singapore - all rights reserved
Keywords: uranium; monomeric U(IV); X-ray absorption spectroscopy; oxidation; beam damage; microbeam.

\section{Introduction}

Monomeric U(IV) is a recently discovered non-crystalline product of $\mathrm{U}(\mathrm{VI})$ reduction by microbes, iron-bearing biogenic minerals and in biostimulated natural sediments (e.g. Bernier-Latmani et al., 2010; Fletcher et al., 2010; Veeramani et al., 2011; Sharp et al., 2011; Cologgi et al., 2011). The species may form along with the crystalline U(IV) phase uraninite, $\mathrm{UO}_{2}(\mathrm{~s})$, in laboratory experiments and in field-scale remediation efforts that aim to reduce U(VI) to less soluble U(IV) species. Key to differentiating U(VI), uraninite and monomeric $\mathrm{U}(\mathrm{IV})$ in environmental samples is the application of $\mathrm{U} L_{\mathrm{III}}$-edge X-ray absorption spectroscopy (XAS) (Kelly, 2010). In particular, element-specific mapping using an X-ray microbeam can be employed to determine the association of heavy metals such as uranium with other elements in the sample, and provide insights into surface species and solid phases (e.g. Bertsch \& Hunter, 2001; Kemner et al., 2004; Punshon et al., 2005). Because of the relatively high incident photon-flux density applied to the sample while using microbeam XAS techniques (Lombi et al., 2011), there is an increased likelihood that uraninite or monomeric U(IV) could be reoxidized during sample analysis. In this study we prepared a set of U(IV)containing samples and a U(VI) standard and analyzed them using both a microbeam and larger beam sizes at the Swiss Light Source (SLS). The goal of our analyses was to determine what conditions, if any, would lead to U(IV) oxidation in our experimental systems.

\section{Experimental}

All experimental systems were prepared in duplicate, and are detailed in Table 1. A hydrous ferric oxide (HFO) was produced by precipitation of a ferric chloride solution using concentrated $\mathrm{NaOH}$ (see Veeramani et al., 2011). The washed HFO was suspended to
$50 \mathrm{~m} M$ as $\mathrm{Fe}(\mathrm{III})$ in a solution containing $400 \mu M \mathrm{U}(\mathrm{VI})$, and all the $\mathrm{U}(\mathrm{VI})$ was quickly adsorbed to the HFO. Uranium dioxide $\left[\mathrm{U}^{\mathrm{IV}} \mathrm{O}_{2}\right]$, hereafter referred to as chemogenic uraninite, was analyzed as received (International Bio-Analytical Industries, Boca Raton, Florida, USA). Monomeric U(IV) and biogenic uraninite were produced via $\mathrm{U}(\mathrm{VI})$ reduction by Shewanella oneidensis MR-1 bacterial cells according to the methods given by Bernier-Latmani $e t$ al. (2010). These bacterial samples were pelleted by centrifugation (10000 $\mathrm{g}$ for $10 \mathrm{~min}$ ) and mounted into Teflon sample holders with Kapton ${ }^{\mathbb{R}}$ tape windows (DuPont, Wilmington, Delaware, USA) in an anaerobic chamber containing $3 \% \mathrm{H}_{2}(\mathrm{~g})$ and a balance $\mathrm{N}_{2}(\mathrm{~g})$. A biostimulated natural sediment from Rifle, Colorado, or RABS sediment (Anderson et al., 2003), containing monomeric U(IV) species (see Sharp et al., 2011) was fixed in epoxy, mounted on glass slides and polished to a thickness of $30 \mu \mathrm{m}$. All samples were transported to SLS in hermetically sealed stainless steel shipping canisters (Schuett-biotec GmbH, Göttingen, Germany) filled to a slightly positive pressure with $\mathrm{N}_{2}(\mathrm{~g})$.

Uranium $L_{\mathrm{II}}$-edge XAS was conducted at the microXAS beamline of the SLS. The beamline layout is described in greater detail by Borca et al. (2009). Using the beamline slits, samples were analyzed with a collimated 'large' beam with sizes of $500 \mu \mathrm{m} \times 500 \mu \mathrm{m}$, and $100 \mu \mathrm{m} \times 100 \mu \mathrm{m}$. The X-ray microbeam was produced by condensing an initial acceptance of $300 \mu \mathrm{m} \times 300 \mu \mathrm{m}$ into a spot of $3 \mu \mathrm{m} \times$ $2 \mu \mathrm{m}$ by employing reflective mirrors. Measurements were performed in fluorescence mode and using a Si drift diode detector. A doublecrystal $\mathrm{Si}(111)$ monochromator (DCM) was used to select energies. During analysis, samples were placed under a constant stream of $\mathrm{N}_{2}(\mathrm{~g})$. Energies were rastered between 17.06 and $17.60 \mathrm{keV}$ for 12.8 min for each scan, and 8-16 scans were collected per sample. Reduction of the XANES raw data was carried out using the ATHENA program (Ravel \& Newville, 2005) by subtracting a 


\section{short communications}

Table 1

Sample list.

Incident fluxes are those collected using the Si photodiode detailed in $\$ 2$.

\begin{tabular}{llll}
\hline Experimental system & $\begin{array}{l}\text { Beam size } \\
(\mu \mathrm{m} \times \mu \mathrm{m})\end{array}$ & $\begin{array}{l}\text { Incident flux } \\
(\mathrm{amps})\end{array}$ & $\begin{array}{l}\text { Oxidation } \\
\text { of U(IV) }\end{array}$ \\
\hline Monomeric U(IV) bound to & $3 \times 2$ & $6.30 \times 10^{-6}$ & Yes \\
Shewanella oneidensis MR-1 & $100 \times 100$ & $2.50 \times 10^{-6}$ & No \\
& $500 \times 500$ & $4.20 \times 10^{-5}$ & No \\
Biogenic uraninite bound to & $3 \times 2$ & $6.30 \times 10^{-6}$ & No \\
Shewanella oneidensis MR-1 & $100 \times 100$ & $2.60 \times 10^{-6}$ & No \\
& $500 \times 500$ & $4.80 \times 10^{-5}$ & No \\
Chemogenic uraninite & $3 \times 2$ & $6.30 \times 10^{-6}$ & No \\
& $100 \times 100$ & $2.50 \times 10^{-6}$ & No \\
RABS sediment with & $500 \times 500$ & $4.18 \times 10^{-5}$ & No \\
monomeric U(IV) & $3 \times 2$ & $6.30 \times 10^{-6}$ & Yes \\
& $100 \times 100$ & $2.50 \times 10^{-6}$ & No \\
HFO with adsorbed U(VI) & $500 \times 500$ & $4.20 \times 10^{-5}$ & No \\
& $3 \times 2$ & $6.30 \times 10^{-6}$ & N/A \\
& $500 \times 500$ & $4.18 \times 10^{-6}$ & N/A \\
\hline
\end{tabular}

background signal (fitted through an appropriate pre-edge range) and normalizing to the main edge jump. The absorption edge was defined as the energy corresponding to the first inflection point (maximum of first derivative).

An ion chamber of reduced dimensions, developed in-house, was used to monitor the incoming beam intensity $\left(I_{0}\right)$ during the spectroscopic measurements, adapting the type of flowing gas with the energy needed. The photon flux of the variable beam sizes was determined using a Hamamatsu Si PIN photodiode (model S359002), analogous to that of Owen et al. (2009). The obtained photon fluxes were in close agreement with theoretical calculations based on known beamline source and optics characteristics. For the large beam sizes, the obtained flux is $2.5 \times 10^{11}$ monochromatic [ $\mathrm{Si}(111) \mathrm{DCM}$ ] photons per second, while, in the microbeam, $0.4 \times 10^{11}$ photons per second were delivered. Assuming a photon energy of $17.2 \mathrm{keV}$, approximately $25 \%$ of incident photons were absorbed in the $200 \mu \mathrm{m}$-thick Si diode (Owen et al., 2009).

\section{Results and discussion}

The objective of the study was to determine X-ray beam conditions under which U(IV) species, including monomeric U(IV) and uraninite, may oxidize to $\mathrm{U}(\mathrm{VI})$. Of particular interest was the potential oxidation induced by X-ray microbeams because of the increased use of microbeams for elemental mapping and spatially resolved EXAFS analyses of uranium-contaminated soils and sediments. No changes in uranium valence state were observed under any beam size $(500 \mu \mathrm{m}$ $\times 500 \mu \mathrm{m}, 100 \mu \mathrm{m} \times 100 \mu \mathrm{m}$ and $3 \mu \mathrm{m} \times 2 \mu \mathrm{m})$ for the chemogenic uraninite, biogenic uraninite or HFO with adsorbed U(VI) experimental systems (Table 1). The oxidation of uranium was observed in the biomass monomeric U(IV) sample and the thin-sectioned RABS sediment. Consequently, the following discussion will focus on these experimental systems.

XANES data from the microbeam analyses of the biomass-associated monomeric U(IV) samples are presented in Fig. 1(a). A marked difference between the first scan (dotted line) and the average of seven subsequent scans (solid line) is observed. In particular, there is a shift in the position and intensity of the white line, and a flattening and rise in the region centred around $17.19 \mathrm{keV}$, marked with arrows. The feature at $17.19 \mathrm{keV}$ is typically associated with $\mathrm{U}(\mathrm{VI})$, probably the more tightly bound axial $\mathrm{O}$ atoms of the uranyl $\left[\mathrm{U}^{\mathrm{VI}} \mathrm{O}_{2}{ }^{2+}\right]$ cation (Kelly, 2010) as is observed for the $\mathrm{U}(\mathrm{VI})$ standard. Therefore, the shift observed between the first and subsequent scans is indicative of uranium oxidation. The averaged spectra for the HFO
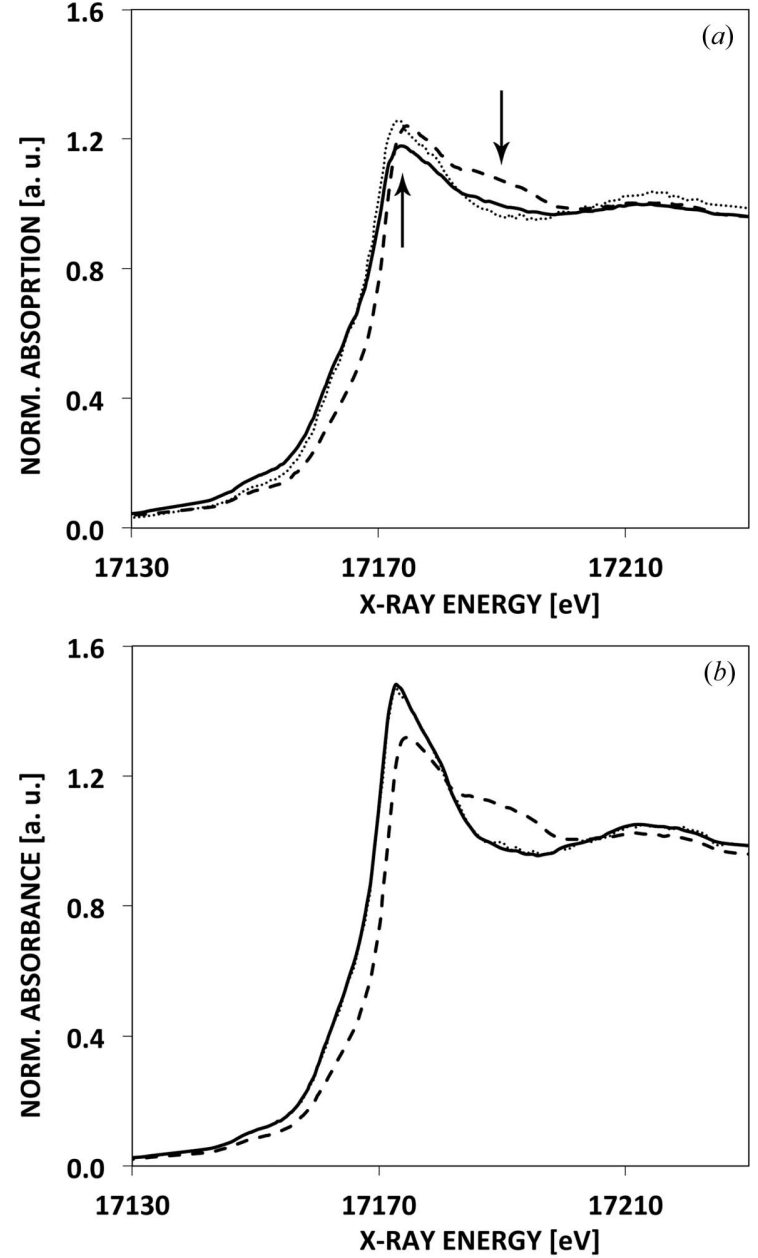

Figure 1

Uranium $L_{\mathrm{III}}$-edge XANES data of monomeric $\mathrm{U}(\mathrm{VI})$ containing biomass, collected under $(a)$ microbeam $(3 \mu \mathrm{m} \times 2 \mu \mathrm{m})$ and $(b)$ large beam $(500 \mu \mathrm{m} \times$ $500 \mu \mathrm{m})$ conditions at the microXAS beamline. A significant change is observed between the first scan (dotted line) and subsequent scans (solid line) of the biomass monomeric U(IV) system under microbeam conditions, likely due to U(IV) oxidation by the microbeam. The subsequent scans show a slight shift in white-line energy and a flattening in the post-edge region centred around $17.19 \mathrm{keV}$, changes indicated with arrows in the figure. These features are present in the HFO + U(VI) system (dashed line), which is included for reference. The changes are not seen under large beam $(500 \mu \mathrm{m} \times 500 \mu \mathrm{m})$ conditions where the initial scan (dotted line) is occluded by the later scans (solid line) due to perfect overlap $(b)$.

$+\mathrm{U}(\mathrm{VI})$ system (dashed line) show the presence of these features in a sample that contains $100 \% \mathrm{U}(\mathrm{VI})$. Fig. $1(b)$ displays XANES spectra collected under large beam $(500 \mu \mathrm{m} \times 500 \mu \mathrm{m})$ conditions. Essentially no change is observed between the initial scan (dotted line) and the average of subsequent scans (solid line) of the biomass monomeric U(IV) sample. Hence, the observed beam damage is attributable to the microbeam conditions $(3 \mu \mathrm{m} \times 2 \mu \mathrm{m})$ rather than the sample run conditions.

Fig. 2 displays the XANES results from the biostimulated RABS sediment containing monomeric U(IV). Similar to the biomass monomeric U(IV) system, there is a large change between the first XAS spectrum (dotted line) and the average of seven subsequent scans (solid line) during microbeam analyses (Fig. 2a). The same shift in the white line and resonance feature at $17.19 \mathrm{keV}$ is also observed, indicative of monomeric U(IV) oxidation in the slide-mounted sediment sample. No change is observed between the first scan (dotted line) and subsequent scans (solid line) when the same sample is analyzed using the $500 \mu \mathrm{m} \times 500 \mu \mathrm{m}$ beam size (Fig. $2 b$ ). 


\section{short communications}
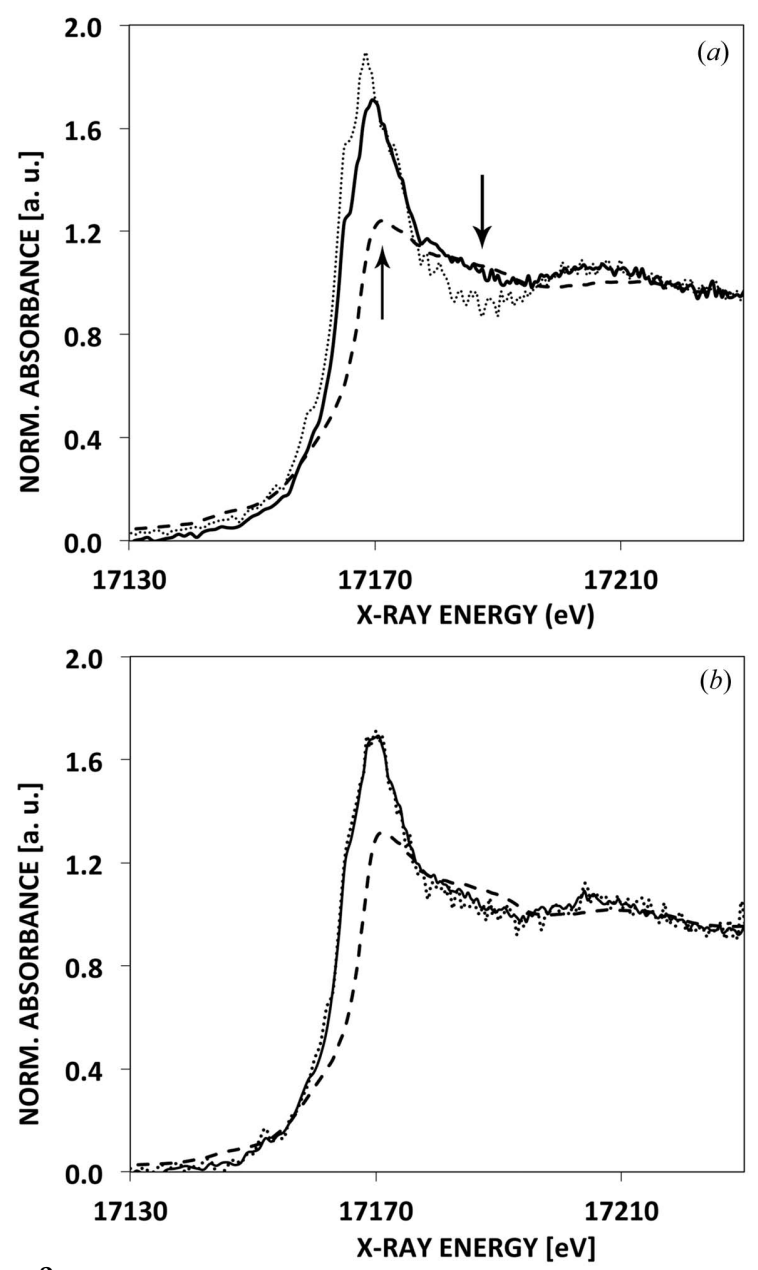

Figure 2

Uranium $L_{\mathrm{III}}$-edge XANES data of sediment from Rifle, Colorado, containing primarily monomeric U(IV) species (see Sharp et al., 2011), collected using (a) the X-ray microbeam and $(b)$ the large beam $(500 \mu \mathrm{m} \times 500 \mu \mathrm{m})$. Oxidation of monomeric U(IV) by the microbeam between the first scan (dotted line) and the average of seven subsequent scans (solid line) is shown by the shift in the white line and particularly the flattening in the post-edge region centred around $17.19 \mathrm{keV}$ (a). A uranyl acetate $\mathrm{U}(\mathrm{VI})$ standard is included for reference (dashed line). There is little change in spectral shape observed between the first scan (dotted line) and the average of nine subsequent scans (solid line) under the large beam $(b)$.

The flux density (photons per $\mu \mathrm{m}^{2}$ ) is more than 6000 times greater under microbeam conditions than the large beam $(500 \mu \mathrm{m} \times 500 \mu \mathrm{m})$ in the two monomeric U(IV) systems. Because of the much smaller spot size used in microprobe analyses, a higher incident flux density is necessary for the collection of XAS data of sufficient quality. The relatively intense beam can lead to dehydration (heating) of hydrated organic samples (e.g. Lombi et al., 2011), and in our study likely lead to the oxidation of redox-sensitive monomeric U(IV) species to $\mathrm{U}(\mathrm{VI})$ after approximately $13 \mathrm{~min}$ of beam exposure.

\section{Conclusions}

XAS analyses of U(VI), uraninite and monomeric U(IV) containing systems indicate that monomeric U(IV) may be oxidized in biomass and sediment samples under X-ray microbeam conditions. Specifically, we show that the microbeam alters the XANES spectra of biomass-associated monomeric U(IV) and monomeric U(IV) contained in natural sediments, consistent with oxidation to U(VI). Those employing X-ray microbeams to perform element-mapping or micrometre-scale EXAFS analyses of samples that may contain monomeric U(IV) should consider that the species may be oxidized owing to the intensity of incoming photons.

The authors thank Kelly Plathe for her assistance in XAS analyses of the samples. DSA was partially supported by a Marie Curie International Incoming Fellowship from the European Commission, grant FP7-PEOPLE-2009-IIF-254143. This work was performed at the microXAS beamline (proposal 20091011) of the Swiss Light Source, Paul Scherrer Institut, Villigen, Switzerland.

\section{References}

Anderson, R. T., Vrionis, H. A., Ortiz-Bernad, I., Resch, C. T., Long, P. E., Dayvault, R., Karp, K., Marutzky, S., Metzler, D. R., Peacock, A., White, D. C., Lowe, M. \& Lovley, D. R. (2003). Appl. Environ. Microbiol. 69, 5884 5891.

Bernier-Latmani, R., Veeramani, H., Vecchia, E. D., Junier, P., LezamaPacheco, J. S., Suvorova, E. I., Sharp, J. O., Wigginton, N. S. \& Bargar, J. R. (2010). Environ. Sci. Technol. 44, 9456-9462.

Bertsch, P. M. \& Hunter, D. B. (2001). Chem. Rev. 101, 1809-1842.

Borca, C. N., Grolimund, D., Willimann, M., Meyer, B., Jefimovs, K., VilaComamala, J. \& David, C. (2009). J. Phys. Conf. Ser. 186, 012003.

Cologgi, D. L., Lampa-Pastirk, S., Speers, A. M., Kelly, S. D. \& Reguera, G. (2011). Proc. Natl. Acad. Sci. USA, 37, 15248-15252.

Fletcher, K. E., Boyanov, M. I., Thomas, S. H., Wu, Q., Kemner, K. M. \& Löffler, F. E. (2010). Environ. Sci. Technol. 44, 4705-4709.

Kelly, S. D. (2010). Synchrotron-Based Techniques in Soils and Sediments, Vol. 34, edited by B. Singh and M. Gräfe, 1st ed, pp. 411-466. Oxford: Elsevier.

Kemner, K. M., Kelly, S. D., Lai, B., Maser, J., O’Loughlin, E. J., SholtoDouglas, D., Cai, Z., Schneegurt, M. A., Kulpa, C. F. \& Nealson, K. H. (2004). Science, 306, 686-687.

Lombi, E., de Jonge, M. D., Donner, E., Ryan, C. G. \& Paterson, D. (2011). Anal. Bioanal. Chem. 400, 1637-1644.

Owen, R. L., Holton, J. M., Schulze-Briese, C. \& Garman, E. F. (2009). J. Synchrotron Rad. 16, 143-151.

Punshon, T., Jackson, B. P., Lanzirotti, A., Hopkins, W. A., Bertsch, P. M. \& Burger, J. (2005). Spectrosc. Lett. 38, 343-363.

Ravel, B. \& Newville, M. (2005). J. Synchrotron Rad. 12, 537-541.

Sharp, J. O., Lezama-Pacheco, J. S., Schofield, E. J., Junier, P., Ulrich, K.-U., Chinni, S., Veeramani, H., Margot-Roquier, C., Webb, S. M., Tebo, B. M., Giammar, D., Bargar, J. R. \& Bernier-Latmani, R. (2011). Geochim. Cosmochim. Acta, 75, 6497-6510.

Veeramani, H., Alessi, D. S., Suvorova, E. I., Lezama-Pacheco, J. S., Stubbs, J. E., Sharp, J. O., Dippon, U., Kappler, A., Bargar, J. R. \& Bernier-Latmani, R. (2011). Geochim. Cosmochim. Acta, 75, 2512-2528. 